\title{
OS SENTIDOS DA DEFICIÊNCIA PELA LIGA BRASILEIRA DE HIGIENE MENTAL
}

LOS SENTIDOS DE LA DISCAPACIDAD POR LA LIGA BRASILEÑA DE HIGIENE MENTAL

THE MEANINGS OF DISABILITY BY BRAZILIAN LEAGUE OF MENTAL HYGIENE

Vivian Ferreira Dias*

Universidade Federal de Santa Catarina

Sandra Caponi**

Universidade Federal de Santa Catarina

RESUMO: Entender a forma como a deficiência é interpretada na atualidade é, também, revisitar os sentidos do passado. Nosso recorte é o domínio médico, e a intenção é trazer, por conseguinte, a forma como o "desvio" era interpretado e investido pela medicina, especialmente quando os sentidos degeneracionistas estavam no auge. São considerados Os Arquivos da Liga Brasileira de Higiene Mental, compreendidos entre 1925 a 1946, e nossas análises se assentam especialmente nos pressupostos da biopolítica - conforme desenvolvidos por Foucault. A sensibilidade da Liga, pois, era a de romper com a assistência médica e social, restringir a entrada de imigrantes de mentalidade anormal, controlar doenças que causariam deficiências e praticar a filantropia seletiva, ou seja, dar auxílio apenas aos mais fortes. Em suma, sob o regime de inferioridade, de atraso à nação, de mal que deveria ser tratado/aniquilado, é que as pessoas com deficiência eram e ainda podem ser significadas.

PALAVRAS-CHAVE: Degeneração. Biopolítica. Deficiência.

RESUMEN: Entender la forma en que la discapacidad es interpretada en la actualidad, también implica revisar los sentidos del pasado. Nuestro recorte es el dominio médico y la intención es traer, por lo tanto, la forma en que el "desvío" era interpretado y creado por la medicina, especialmente cuando la teoría degeneracionista estaba en su auge. Se analizan "Los Archivos de la Liga Brasileña de Higiene Mental", comprendidos entre 1925 a 1946. Nuestro análisis se basa, especialmente, en los presupuestos de la biopolítica - conforme desarrollados por Foucault. La sensibilidad de la Liga, pues, era romper con la asistencia médica y social, restringir la entrada de inmigrantes considerados de mentalidad anormal, controlar enfermedades que causarían discapacidades y

\footnotetext{
* Doutora em Ciências Humanas pela UfSC. Fonoaudióloga da Coordenadoria de Acessibilidade Educacional/CAE/SAAD/UFSC.E-mail:vivian.dias@ufsc.br.

** Professora Titular do Departamento de Sociologia e Ciências Políticas e do Doutorado Interdisciplinar em Ciências Humanasda Universidade Federalde Santa Catarina. E-mail: sandracaponi@gmail.com.
} 
practicar la filantropía selectiva, o sea, dar auxilio sólo a los más fuertes. En suma, bajo el régistro de inferioridad, de atraso a la nación, de mal que debería ser tratado / aniquilado, es que las personas con discapacidad eran y aún pueden ser significadas.

PALABRAS CLAVE: Degeneración. Biopolítica. Discapacidad.

ABSTRACT: Understanding how disability is interpreted today is also to revisit the senses of the past. We focus on the medical domain with the intention to explain and understand how "deviation" was interpreted and invested within medicine, especially during the heyday of the degenerationist senses. The Archives of the Brazilian League of Mental Hygiene, from 1925 to 1946, are taken in account and our analysis are particularly based on the assumptions of biopolitics - as developed by Foucault. The League's sensitivity was to break with medical and social assistance, to restrict the entry of immigrants of abnormal mentality, to control diseases that would cause disabilities and to practice selective philanthropy, that is, to aid only the strongest. In short, it is from under the regime of inferiority - of delay to the development of the nation, of that evil that should be treated / annihilated - that people with disabilities were and can still be signified..

KEYWORDS: Degeneration. Biopolitics. Disability.

\section{CONSIDERAÇÕES INICIAIS}

A rede discursiva na qual a pessoa com deficiência se inscreve está historicamente vinculada à falta. Por mais que o termo, atualmente em uso, para nomear quem tem deficiência seja "pessoa com deficiência" (ter surdez, ter tetraplegia, por exemplo), no limite, ser alguém com deficiência ${ }^{1}$ é para o senso comum - e ouso dizer que para a maioria das pessoas - ter perdido ou jamais tido alguma capacidade funcional ou parte do corpo. É uma identidade que, grosso modo, é constituída não pelo o que se tem ou se acredita ter, mas por aquilo que falta.

Obviamente, falta ou presença é algo bem pouco objetivo. É necessário, pois, um parâmetro prévio, um modelo ideal que norteie essa atribuição. Assim, a deficiência existe porque existe a "normalidade" e precisamente com esse sentido de funcionamento ideal, ótimo - como se não houvesse variações. Porém, contraditoriamente, a deficiência é atribuída a alguém justamente quando a "normalidade" escapa ${ }^{2}$.

No entanto, é possível pensar sob outra perspectiva. Uma anomalia não implica necessariamente uma patologia, ainda que o patológico possa ser visto como uma anormalidade. A anomalia pode ser uma categoria neutra. Portanto, para Canguilhem (2009), não se trata de diferenciar propriamente o estado normal do patológico, tampouco admitir a continuidade irrestrita de ambos ou mesmo determinar uma ordem de valoração, positiva ou negativa. As duas dimensões são inerentes à vida. Ademais, não é equívoco admitir que algo possa trazer reflexos de outro (admitindo a imbricação do normal e do patológico), sem negar suas próprias características. Em outras palavras, o patológico guarda relação com o normal sem, no entanto, deixar de apresentar particularidades que lhe definem como tal. E, sobretudo, como bem menciona Canguilhem (2009), é preciso entender a doença como algo que afeta o organismo como um todo e não apenas uma função ou órgão isolado. É toda uma rede concatenada e inter-relacionada que se afeta no estado patológico. Pensamento semelhante pode ser atribuído à deficiência.

No entanto, a falta e o desvio podem ter interpretações diferentes das trazidas por Canguilhem, que compreende a patologia como uma dimensão neutra, uma vez que essas condições - falta e desvio - prioritariamente se atrelam a sentidos negativos,

\footnotetext{
${ }^{1}$ Optei, ainda que ciente da repetição, por utilizar o termo "pessoa com deficiência", sem a substituição por qualquer outro referente ou sigla, durante todo o texto. Isso porque, esse é o termo (oficial) vigente no Brasil, escolhido pelas próprias pessoas com deficiência e nenhum outro me parece adequado na empreitada que pretendo seguir.

${ }^{2}$ De acordo com Canguilhem (2009), o estado patológico ou anormal não é consequência da ausência de qualquer norma. A doença é ainda uma norma da vida, mas uma norma inferior, no sentido que não tolera nenhum desvio das condições em que é válida, por ser incapaz de se transformar em outra norma. O ser vivo doente está normalizado em condições bem definidas e perdeu a capacidade normativa, ou seja, a capacidade de instituir normas diferentes, sob condições diferentes, diversas. Não há distúrbio patológico em si, o anormal só pode ser apreciado em uma relação.
} 
historicamente construídos, de incapacidade e invalidez. Porém, estamos vivendo um momento no qual a inclusão é a palavra de ordem, por conseguinte, as práticas de exclusão e marginalização são colocadas em xeque. Isso significa que, diferentemente de outros períodos históricos, a pessoa com deficiência, em tese, tem mais visibilidade. No entanto, as descontinuidades e as dispersões de certas ordens, especialmente em meio a um processo historicamente excludente, se repetem. E, notoriamente, o processo de inclusão não se realiza somente por meio de leis e cotas ${ }^{4}$.

Isso porque adequações estruturais e materiais não são suficientemente potentes para permitir que a acessibilidade seja instituída, uma vez que a inclusão também se faz por meio de ações e práticas acessíveis: produção de conhecimentos/saberes e experiências exitosas de inclusão social, mas sobretudo acreditamos que os discursos e as práticas que subjetivam a pessoa com deficiência também estão diretamente ligados à (in)viabilidade da inclusão. Em outras palavras, entender a inclusão/exclusão é compreender a forma como a (a)normalidade foi enunciada, é tomar a deficiência e, por conseguinte a pessoa com deficiência, como objetos de discursos. Discursos entendidos como uma série de práticas que formam os objetos de que falam (FOUCAULT, 1997) e que sob determinadas condições: circunscrevem, enunciam e produzem aquilo que é o dizível e o legível, segundo Deleuze (2013), de uma determinada época.

Compreender a forma como a pessoa com deficiência vem sendo subjetivada pelos discursos pode ser uma maneira profícua de entender os processos de (ex/in)clusão e a trama que costurou os sentidos da (a)normalidade. Ademais, entender a forma como a deficiência e as pessoas com deficiência são interpretadas/subjetivadas na atualidade é também revisitar os sentidos do passado. Dito de outro modo, a sensibilidade que cerca a deficiência, hoje, reflete determinados momentos históricos, com os deslocamentos inerentes a cada nova tomada de palavra, mas guardando relações com os mais remotos (FOUCAULT, 1996).

Nosso recorte é o domínio médico, dimensão extremamente ligada à categoria deficiência - uma vez que fortemente atrelado à atribuição dos diagnósticos e às práticas de apagamento dos sinais e sintomas. Nesse viés, a intenção é trazer a forma como o "desvio" era interpretado e investido pela Medicina, prioritariamente quando os pressupostos degeneracionistas estavam no auge, de modo a compreender a série que liga esses sentidos à forma como a deficiência é hoje interpretada e investida. São considerados "Os Arquivos da Liga Brasileira de Higiene Mental”, compreendidos entre 1925 a 1946, e nossas análises se assentam, especialmente, nos pressupostos da biopolítica, conforme desenvolvidos por Foucault.

Os Arquivos da Liga Brasileira de Higiene Mental ${ }^{5}$ trazem dados significativos da sensibilidade do início do século passado e da forma como o "desvio" era interpretado e investido pela Medicina. Fundada por Gustavo Riedel, a Liga Brasileira de Higiene Mental iniciou sua atuação em 1923. Sua sede ficava no Rio de Janeiro, mas havia membros espalhados pelas mais diversas regiões do país. Eram 10 delegados nos seguintes estados: Rio Grande do Sul, Santa Catarina, São Paulo, Minas Gerais, Rio de Janeiro, Rio Grande do Norte, Bahia, Pernambuco, Pará e Amazonas. De acordo com Seixas, Mota e Zilbreman (2009), a Liga nasceu em uma conjuntura histórica fortemente marcada pela Ideologia Positivista - ideais de modernidade, ordem, progresso e racionalidade balizavam seus fazeres. Os psiquiatras não só acreditavam nos componentes biológicos e genéticos, mas que os estigmas físicos e morais tendiam a piorar, num processo de degeneração progressiva. A degeneração era, portanto, compreendida para além de uma doença individual, como uma ameaça social.

\footnotetext{
${ }^{3}$ Estamos tomando a inclusão na perspectiva da acessibilidade, ou seja, no convívio entre todos, de modo que todas as corporeidades sejam incorporadas, sem a necessidade de aproximação com a normalidade. Para Sassaki (1997), o movimento de inclusão - que foi precedido por práticas de exclusão, atendimento segregado dentro de instituições e práticas de integração - tem por objetivo construir uma sociedade que seja para todos. Essa construção, para o mesmo estudioso, se assentaria na celebração da diferença, na valorização da diversidade, na solidariedade humana, na importância das minorias, no direito ao pertencimento e, especialmente, no exercício da cidadania com qualidade de vida.

${ }^{4}$ Há uma vasta legislação sobre a acessibilidade. Destacamos, no entanto, duas leis que tratam mais especificamente de cotas voltadas às pessoas com deficiência: (1) a Lei 8.213, também denominada Lei de Cotas, voltada à questão trabalhista, preconiza em seu artigo 93 que a empresa com 100 ou mais funcionários está obrigada a preencher, na porcentagem de 2 a 5\%, a depender de seu efetivo, seus cargos com beneficiários reabilitados ou pessoas com deficiência. E (2) a Lei 13.409, de 28 de dezembro de 2016, que altera a Lei 12.711, dispõe sobre a reserva de vagas para pessoas com deficiência nos Cursos Técnicos de Nível Médio e Superior das Instituições Federais de Ensino.
}

${ }^{5}$ Organizados e disponibilizados pelo “Grupo de Estudos e Pesquisas Higiene Mental e Eugenia”, da Universidade Estadual de Maringá (UEM, 2017). 


\section{UMA LONGA TRAJETÓRIA: DEFICIÊNCIA E DEGENERAÇ̃̃O}

No que diz respeito à história da deficiência - seus sentidos, discursos e práticas - na Idade Moderna, segundo Lima e Costa (2014), vigoram os princípios da normalidade. Nessa perspectiva, a Medicina passa a se ocupar da deficiência e a produzir novos saberes sobre essa dimensão: mais racionais e objetivos. Assim como se apropriou da convulsão, antes circunscrita à religião, a Medicina também se ocupou da deficiência, que agora de forma mais notória ampliava seus limites de sentidos, abandonando formalmente o signo diabólico. Com isso, a deficiência passa a ser definida, circunscrita e problematizada como uma dimensão orgânica, palpável, e sobre a qual o médico tem o estatuto legitimado para construir sua verdade. Veja que essa relação saber/poder é tão arraigada na formação discursiva da deficiência que ainda vigora. Qualquer procedimento que tenha como meta a verificação da deficiência ainda solicita um laudo - a materialização de um saber técnico sobre a deficiência, com códigos específicos, com toda uma maquinaria de testes e escores que falam sobre o déficit. E aquele que produz esse discurso, que não pode ser qualquer um, há de ocupar o espaço discursivo da autoridade médica.

Sem dúvidas, hoje há uma nova maquinaria para atribuição da deficiência, pautada na funcionalidade e numa distribuição do poder de inspecionar dividido entre muitos profissionais e não mais restrito à figura do médico ${ }^{6}$. Mas essa prática ainda não significa, ainda não está sistematizada, nem cristalizada, portanto, reservamo-nos o direito de dizer que a supremacia da Medicina na atribuição da deficiência ainda se repete. Entretanto, há de se ressaltar que quando a Medicina passa a entrar na série de procedimentos que visam a controlar a deficiência, a institucionalização se constitui como prática que aciona mecanismos de normalização, e, embora exista uma aparente tentativa de acolhimento, os sentidos de isolamento e de assistencialismo se sobressaem.

Segundo Caponi (2000), na transição da Idade Média para a Moderna, aos pobres eram destinadas práticas de assistencialismo e de ajuda. Mas a pobreza, nessa perspectiva, não tinha um caráter unicamente financeiro/econômico, isso porque na categoria "pobres" estavam as viúvas, os órfãos, os doentes, os velhos, os insanos e as pessoas com deficiência. Ou seja, todas aquelas pessoas tidas como vulneráveis e que deveriam viver da caridade estavam misturadas. A pobreza, nesse caso, é aquela do plano do desfortúnio, da comiseração: manter essas pessoas excluídas dos demais tinha um sentido de coação, de controle e de inferiorização. Para Pereira (2009), essa época foi essencial para a formação discursiva da invalidez, da incapacidade e, por conseguinte, da inferioridade das pessoas com deficiência.

Na Idade Contemporânea, portanto, a Medicina consolida seu papel de controle do anormal, coadunada com o localizacionismo cujo regime de verdade mostra que há substratos neurológicos e físicos na materialização da deficiência - porque, conforme apontado por Harlos, Harlos e Denari (2012), a classificação dos indivíduos em função do cientificismo passou a levar em conta a dimensão biológica e cabia ao médico tanto a rotulação quanto os cuidados. Além disso, com o advento do Iluminismo e do desenvolvimento científico foi alcançada uma maior compreensão sobre a deficiência e muitos direitos passaram a ser garantidos. Há, nessa perspectiva, uma sobreposição de verdades - o que permite à pessoa com deficiência se apropriar de outras subjetividades ao transitar por diferentes campos de saber: o misticismo, a religião, a medicina e a ciência. Os ideais de igualdade e liberdade começam a invadir os redutos destinados a tratar as existências atípicas. Mas esses redutos seguiram firmes por muito tempo; $o$ mecanismo de reabilitação vigora por longos anos. O corpo deficiente é submetido à normalidade.

Nessa perspectiva, para Pacheco e Alves (2007), o avanço da Medicina permitiu duas dispersões essenciais na formação discursiva da anormalidade, até então atrelada à religião e ao abandono: (1) ela se descola da temática moral/teológica - a pessoa com deficiência não é alguém vítima de uma maldição ou responsável por um grave pecado e (2) permite que o hospital deixe de ser um depositário de pessoas, de excluídos, sem qualquer preocupação com os aspectos psicossociais. Ainda para as mesmas autoras, todos os aspectos apresentados na história da deficiência não são dimensões superadas e que tenham ficado no passado, ou seja, elas

\footnotetext{
${ }^{6}$ De acordo com a mais nova legislação brasileira sobre a deficiência, a Lei 13.146, de $2015, \S 1^{\circ}$ A avaliação da deficiência, quando necessária, será biopsicossocial, realizada por equipe multiprofissional e interdisciplinar e considerará: I - os impedimentos nas funções e nas estruturas do corpo; II - os fatores socioambientais, psicológicos e pessoais; III - a limitação no desempenho de atividades; e IV - a restrição de participação.
} 
coexistem e insistem.

Nesse sentido, mesmo com a visão mais científica acerca da deficiência, e talvez justamente por isso, a noção de degeneração (de "mal" transmitido hereditariamente) era extremamente forte e hoje não podemos dizer que esteja completamente superada: ela constitui o sentido da deficiência. Aliás, a teoria da degenerescência apresentada por Morel, de acordo com Walber e Silva (2006) e Pessoti (1984), substituiu a noção de condenação divina, especialmente referente à pessoa com deficiência intelectual, para a condenação da natureza.

Caponi (2012), ao propor uma genealogia da psiquiatria ampliada, no livro Loucos e Degenerados, apresenta um rico material sobre a degeneração: desde sua emergência até suas influências sobre a psiquiatria contemporânea ainda vigente. Caponi (2012) relata que se antes eram os delírios e alucinações os sinalizadores da loucura, a psiquiatria passou, no entanto, a se voltar cada vez mais para atos corriqueiros, para pequenos desvios, o que permitiu a sua literal ampliação. Obviamente, foram percebidos deslocamentos entre as ideias de Morel e as apresentadas atualmente. No entanto, se antes a hereditariedade tinha tanto peso quanto as paixões desenfreadas, como era para Pinel, ou seja, apenas uma causa dentre tantas, foi-se atribuindo cada vez mais peso para a herança mórbida. A necessidade de um discurso e práticas mais objetivas para o fortalecimento e legitimação da psiquiatria foi o terreno necessário para que as histórias pessoais passassem a ser silenciadas em detrimento de sinais físicos, de doenças prévias na família e mesmo do conhecimento da bioquímica cerebral e de protocolos avaliativos, como os apresentados por Kraepelin.

Por esse viés, os sofrimentos atrelados e inerentes à vida são reduzidos a concentrações de neurotransmissores e, por conseguinte, passam a ser medicalizados. As queixas do paciente são menos ouvidas que os sinais que apresenta, daí a explicação para que diagnósticos sejam fechados por meio de check lists de sintomas, na atualidade. Embora, ainda de acordo com Caponi (2012), essa supremacia biologizante tenha ficado adormecida até por volta dos anos 70 do século passado, em função da expansão da psicanálise, há posteriormente uma retomada do discurso que busca tornar a psiquiatria corporal - no sentido de palpável, rastreável.

No período no qual ainda não havia avanço necessário para que o cérebro, o órgão sede dos pensamentos e da moral, fosse rastreado, houve uma incursão no corpo expandido, ou seja, na família. Buscavam-se indícios de sinais mórbidos que pudessem explicar a doença do paciente. Tanto para Morel, que defendia o tratamento moral, quanto para Kraepelin, que pregava a psiquiatria preventiva, a intenção não era apenas a de criar critérios diagnósticos, mas de fato estabelecer um controle do espaço social. Obviamente há diferenças entre esses pensamentos. Morel, mais otimista, acreditava na eficácia das intervenções sociais higiênicas do meio social, pelo controle das infecções e das condições insalubres de trabalho e criação de asilos, por exemplo. Kraepelin entendia que essas medidas eram um obstáculo à purificação da raça, portanto, seus preceitos eram nitidamente eugênicos, ou seja, ele perseguia a regeneração da raça e a neutralização dos perigos que ameaçavam essa pureza (CAPONI, 2012).

Mas é preciso ressaltar que as práticas de extermínio e esterilizações ficaram reservadas às ações eugênicas e aí estão explicitadas algumas das principais diferenças entre o eugenismo e a degeneração. Além dessa, podemos citar que os degeneracionistas tendem a atribuir um papel preponderante ao meio na possibilidade de regeneração, noção não compartilhada pelos eugenistas, os quais acreditavam que o controle do ambiente inclusive atrapalhava a natural aniquilação dos menos preparados para a vida. No entanto, guardadas as diferenças entre degeneração e eugenia, ambas partiam da detecção de sinais e comportamentos indesejáveis, desviados do padrão normal, aliás, tomavam por base o homem médio normal: “[...] nem muito grande, nem muito pequeno, o homem não deve ter os cabelos muito lisos nem cacheados, o ventre deve ser reto, mas ligeiramente arredondado, deve ter músculos, mas sem exageração" (RICHET, 1922, p.151).

Essa mesma lógica degeneracionista é a que permite atualmente que quaisquer desvios ou predisposições genéticas sejam compreendidos como fatores predisponentes e preditivos de tais e tais enfermidades e que praticamente todas as dimensões possam, em algum momento, atingir o status de desvio. É a medicalização do não patológico nas palavras de Foucault (2001).

Embora essas práticas estejam mais atreladas a diagnósticos psiquiátricos, e o escopo do trabalho de Caponi (2012) seja justamente esse, é possível estabelecer correlações com a deficiência de forma mais global. As práticas atreladas à deficiência ainda passam pela 
esfera preventiva. Os aconselhamentos genéticos e a intervenção precoce se pautam na lógica da degeneração. A herança mórbida explica o déficit e anuncia a propagação da deficiência. E, como na maior parte das vezes ela é condição que não pode ser tratada, o "ataque" só é possível quando ela é ainda um devir.

Nessa perspectiva da hereditariedade mórbida, a pessoa nasceria com uma predisposição tal, imposta pela natureza, adquirida por seus parentes e repassada aos seus descendentes. É um mal hereditário que se espraia, nessa concepção. O demônio sai de cena, o castigo do criador também, mas a degenerescência transmite um fardo ainda mais pesado à pessoa detentora do desvio. Ela não só é a materialização do erro, como ela é potencialmente disseminadora desse erro. A degenerescência ocupa, de modo mais objetivo, o lugar de categoria de (des)controle da normalidade.

Ainda hoje a deficiência (lesão) impõe dois riscos/perigos (no viés biológico, que impacta o corpo): (1) se ela "passa", ou seja, se é contagiosa e (2) se é hereditária, transmitida dos pais para os filhos. A noção de degeneração insiste. Aliás, mesma constatação realizada por Caponi (2012), conforme já referimos há pouco. A hereditariedade é o fio que atravessa a história da psiquiatria e de algum modo alinhava a história do próprio corpo, da saúde e da doença. A predisposição genética e a sobreposição de diagnósticos interligados (um pequeno desvio que anuncia outros mais graves), bem como a lógica da expansão dos diagnósticos, têm a intenção de cooptar cada vez mais pessoas, em uma trama que nada escapa, onde tudo é investido enquanto é tempo.

\section{BIOPODER E DEFICIÊNCIA}

Inicialmente, o biopoder ${ }^{7}$ era voltado ao corpo individual, no sentido de torná-lo dócil, higiênico e produtivo. Essa noção de poder está notoriamente atrelada aos ideais do trabalho, do capitalismo: é, pois, sobre o corpo e em relação ao corpo que o controle é exercido (FOUCAULT, 2004b). E, nesse sentido, os sistemas de vigilância também são colocados em ação.

Dito de outro modo é sobre o corpo que se produzem verdades e saberes (FOUCAULT, 2005a) e cabem à Medicina a veiculação e ratificação deles, ou seja, o poder deixa de ser essencialmente poder de morte para passar a ser um poder referido à vida, ao biológico, ao corpo de indivíduos e populações.

Ao tratar da governamentalidade, essa regulação do comportamento da população - em uma perspectiva que admite a moral, os valores e a ética como dimensões que têm história -, o dispositivo surge como categoria na análise foucaultiana. A noção de dispositivo em Foucault (2008b) está atrelada à descrição genealógica, ou seja, à análise do poder na relação entre o discurso e o não discurso. Além disso, o dispositivo, a partir de Foucault (1979), é compreendido como um conjunto relacionado a meios (leis, o não dito, instituições, discursos) de controlar o comportamento de outrem. Disso decorre que o conceito de dispositivo, para Foucault, está extremamente vinculado à dimensão do biopoder.

Uma das teses defendidas pelos pressupostos foucaultianos é a de que o dispositivo disciplinar - atrelado à anatomopolítica dos corpos - poderia ser bem observado como complemento ou continuidade do discurso jurídico/penal. E é possível acrescentar ainda que nos anormais existe um deslocamento da noção de poder, da repressão para a correção, ou seja, o poder passa a ter uma conotação positiva, no sentido de readaptação. A anatomopolítica, para Foucault (2005a), diz respeito ao dispositivo de controle do corpo individual e tem a normalidade como sua precursora.

Já o dispositivo de segurança (biopolítica), na perspectiva foucaultiana, é compreendido como uma rede de relações que são voltadas à população. A população, pois, desde o nascimento, é submetida a uma constante vigília. Em relação ao meu objeto, aplica-se esse controle na população para tentar aniquilar a possibilidade de ocorrência da deficiência e em caso de insucesso submeter o sujeito (controle disciplinar) à reabilitação precoce. Obviamente que em relação à deficiência esse controle tem outras facetas. O

\footnotetext{
${ }^{7}$ Foucault assevera que, em um determinado momento histórico, o poder soberano se constituía como um poder sobre a morte - fazer morrer ou deixar viver. Foucault aponta, no entanto, que a partir do século XVIII começa a se praticar um poder que se centra na vida. A lógica agora passa a ser outra: fazer viver ou deixar morrer. Isso justifica todos os cálculos e estatísticas sobre nascimentos, mortes, doenças. É sobre a vida e sobre o corpo que o controle se dá (FOUCAULT, 2005a).
} 
aconselhamento genético de famílias que possuem casos de deficiência na família é um exercício biopolítico. Até mesmo as campanhas de conscientização no trânsito que tentam prevenir possíveis acidentes que podem culminar em deficiências, bem como exames do pezinho, orelhinha e olhinho ${ }^{8}$, fazem parte dessa mesma estratégia biopolítica.

O controle dos corpos, nas palavras de Foucault, é bem compreendido na passagem que segue: "Deveríamos falar de biopolítica para designar o que faz com que a vida e seus mecanismos possam entrar no domínio de cálculos explícitos e o que transforma o saberpoder num agente de transformação da vida humana" (FOUCAULT, 2005a, p. 170). Nessa mesma direção, de acordo com Caponi (2014, p. 754):

\begin{abstract}
Saber antecipar os riscos, estar devidamente informado e agir de acordo às exigências impostas pelos últimos estudos epidemiológicos, psiquiátricos e médicos, se impõe como um dever moral a todos nós e de maneira idêntica. Se o dispositivo de segurança pode articular-se com o modo liberal de governar, é porque este tipo de gestão biopolítica das populações se baseia na confiança absoluta, na difusão de informações que se apresentam como neutrais e objetivas, e que sutilmente somos levados a aceitar e a integrar a nossas vidas.
\end{abstract}

Foucault (2005a) aponta a sexualidade como a dimensão que sintetizaria os dispositivos disciplinares (anatomopolítica) e de segurança (biopolítica), já que localizada na encruzilhada do corpo e da população. Nessa direção, nossa hipótese é a de que no campo da deficiência temos também um lugar privilegiado para entender o exercício do anatomopoder, do biopoder, dos dispositivos disciplinar e de segurança, além da constituição do anormal.

Esse espaço privilegiado se justifica também na medida em que essa noção de anormalidade está deslocada da ideia de perigo (no sentido de violência), de criminalidade em potencial (como no caso do criminoso anormal e mesmo dos sentidos pejorativos atrelados aos diagnósticos ligados à sexualidade). O sentido "deficiência" vem revestido da noção de desfortúnio, de "normalidade" frágil, mas, também, de superação e enfrentamento.

Compreendemos a deficiência, portanto, como uma dimensão que conjuga o corpo e a população. O corpo, porque a deficiência está de fato inscrita de modo objetivo na dimensão física da pessoa - é pressuposto da deficiência ter uma lesão/"disfunção" ${ }^{2}$. E a população, porque a deficiência é sentida como problema de saúde pública: precisa ser evitada, prevenida, e, por conseguinte, são criadas/administradas instituições e organizações que prestam assistência e existe toda uma maquinaria que visa a detectar a deficiência precocemente no grupo. Em suma, a vontade da inclusão divide espaço com a vontade de apagamento da deficiência.

\title{
4 A NORMALIDADE COMO UM SENTIDO E A MEDICALIZAÇÃO DA HUMANIDADE
}

Há vários dispositivos de normalização, porém, a autoridade para arbitrar acerca de quais são os parâmetros e limites da normalidade está fortemente ligada à Medicina. Uma das passagens que mostram a insistência e a repetição dos saberes que refletem o poder exercido pela Medicina pode ser apreciada ainda no início do livro "O nascimento da clínica":

A Medicina não deve mais ser apenas o corpus de técnica da cura e do saber que elas requerem; envolverá, também, um conhecimento do homem saudável, isto é, ao mesmo tempo uma experiência do homem não doente e uma definição do homem modelo. [...] é importante determinar como e de que maneira as diversas formas do saber médico se referem às noções positivas de saúde e de normalidade. [...] A Medicina do século XIX regula-se mais, em compensação, pela normalidade do que pela saúde (FOUCAULT, 2004a, p. 37).

Ou seja, aquilo que foi instituído ao final do século XIX - quando a normalidade passa a ser um signo que norteia o fazer médico, mais que a doença - ainda é um sentido que baliza os discursos que circulam sobre o corpo e, especialmente, sobre a deficiência. Por

\footnotetext{
${ }^{8}$ Teste do pezinho: o objetivo é diagnosticar e tratar precocemente doenças que podem causar deficiência intelectual (o sangue a ser analisado é retirado dos pés do bebê e por isso leva esse nome). Teste da orelhinha: por meio de um exame (que detecta as emissões otoacústicas do ouvido interno) é possível detectar precocemente a deficiência auditiva, com vistas à intervenção. Teste do olhinho: é a aferição do reflexo da pupila, a partir de uma fonte de luz. Ele é capaz de detectar, precocemente, uma série de doenças oculares (MINISTÉRIO DA SAÚDE, 2018).
}

${ }^{9}$ De acordo com Diniz (2007, p.78) “[...] há algo de particular no modo de vida da deficiência, que é o corpo com lesão”. 
conseguinte, ainda que com as dispersões ocorridas, a pessoa com deficiência é considerada desviante da norma e, ao mesmo tempo, capturada por ela, na medida em que todos os investimentos realizados sobre o corpo com deficiência têm a normalidade como meta.

Assim, da mesma forma que a sexualidade, como mencionado, igualmente a deficiência está na encruzilhada entre corpo individual e população (FOUCAULT, 2005a). Logo, ela depende da disciplina e da regulamentação. Inclusive, não podemos falar de resistência do sujeito à captura por essa maquinaria, uma vez que a deficiência pode cooptar qualquer um, a qualquer tempo, independentemente de sua vontade.

Nessa perspectiva, nenhum domínio do saber é mais autorizado a falar que a Medicina: A Medicina é um saber-poder que incide ao mesmo tempo sobre o corpo e sobre a população, sobre o organismo e sobre os processos biológicos e que vai, portanto, ter efeitos disciplinares e efeitos regulamentadores. A Medicina investe na normalização do corpo deficiente, define a linha que separa o normal do patológico e autoriza o gozo dos direitos da pessoa com deficiência (nenhum benefício é concedido sem a caneta do médico). O nascimento da clínica mostra a passagem da salvação da alma para a salvação do corpo. Salvar a alma era algo que dependia da misericórdia celestial. Passou-se, pois, a depender da habilidade do médico. A Medicina assume poderes quase divinos.

Em relação ao nascimento do hospital, no entanto, apenas no século XIX ele passou a ser prioritariamente médico. O hospital nem sempre teve o viés de cura que tem hoje - ele era incialmente um depósito de miseráveis, e mais, um morredouro nas palavras de Foucault: tinha o viés da assistência, mas, essencialmente, separação e exclusão - não é para curar, mas para acolher o pobre que está morrendo - perigoso porque pode contagiar a população (FOUCAULT, 1979). Politicamente, ele surge quando se viu a possibilidade de devolver a saúde aos soldados feridos (custosos, portanto, não poderiam morrer - vigiados para que fossem curados, para que não desertassem, tampouco simulassem a continuidade da doença). A disciplinarização e a vigilância passam a fazer parte do ambiente hospitalar e os saberes médicos sofrem também deslocamentos - a inteligibilidade da doença é dada pela botânica, logo, as dimensões externas precisam ser controladas. É isso que permite a medicalização do hospital.

E é isso que permite a medicalização da deficiência, por conseguinte. Também foi o cenário dos feridos em guerras que "inventou" a reabilitação. Também foi esse controle de agentes externos: campanhas de trânsito, controle de acidentes de trabalho, vacinação da população, exames nas gestantes e nos recém-nascidos, que trouxe novos saberes ao campo da deficiência - controle, cuidado e disciplina para evitá-la.

Ora, agora que o poder é cada vez menos o direito de fazer morrer e cada vez mais o direito de intervir para fazer viver, e na maneira de viver, e no "como" da vida, a partir do momento em que, portanto, o poder intervém, sobretudo, nesse nível para aumentar a vida, para controlar seus acidentes, suas eventualidades, suas deficiências, daí por diante a morte, como termo da vida, e evidentemente o termo, o limite, a extremidade do poder. Ela está do lado de fora, em relação ao poder: e o que cai fora de seu domínio, e sobre o que o poder só terá domínio de modo geral, global, estatístico. Isso sobre o que poder tem domínio não é a morte, é a mortalidade (FOUCAULT, 2005b, p. 295-296).

É, pois, a biopolítica, esse controle que se faz sobre a vida - e que insiste nos dias de hoje - que institui a ideia de racismo (no sentido biológico) de atrelar a noção de anormalidade à pessoa com deficiência. Por conseguinte, é em nome desse racismo que abortar uma criança, cujos exames pré-natais detectaram alguma deficiência, é mais autorizado, inclusive moralmente, que interromper a gestação de um bebê considerado saudável. Essa constatação nos remete à noção de vida nua, conforme preconizada por Agamben (2002), acerca das existências destituídas de valor e que não merecem ser vividas.

Agamben (2002) parte do conceito de homo sacer - uma figura arcaica e jurídico/política do Direito Romano. Ao ser proclamada sacer, a pessoa era excluída do direito e da política da cidade. Ainda que essa pessoa não pudesse ser legalmente morta, qualquer um poderia matá-la - sem que lhe fosse imputada culpa. Destituída de seu papel político, tem-se apenas a Vida Nua, biológica, sem valor, e, portanto, matável. O homo sacer está na encruzilhada entre a exclusão e a inclusão. Matável por estar fora do direito e inimputável pelo mesmo motivo. Está e não está entre todos. O que justifica um poder pautado na vida deixar morrer é justamente o racismo, a eugenia, o evolucionismo (FOUCAULT, 2005b). 
Na obra Os anormais, mais especificamente na aula de 22 de janeiro de 1975, a noção de monstruosidade trazida por Foucault não diz respeito apenas aos comportamentos do sujeito, mas também a uma dimensão física que fomenta tal pensamento. A transgressão do limite natural, entendido como monstruosidade por Foucault, de certo modo é também a definição da deficiência.

O anormal remete tanto a uma esfera fixa, médias estatísticas, valores e parâmetros; quanto valorativa, referente aos comportamentos e ações. Está entre o médico (a ser tratado) e o jurídico (a ser punível?) (CAPONI, 2009). Ou seja, é considerado pela sociedade como jurídica e medicamente perigoso, nocivo. O anormal apresenta, ao mesmo tempo, desvio da média e ameaça às normas (CANGUILHEM, 2009, p. 204).

Conforme preconizada por Foucault (2008b), a normalização consiste no estabelecimento de um modelo ótimo e os comportamentos, gestos e funcionalidades são moldados no sentido de que se aproximem da norma. Os sentidos, normal e anormal, só são possíveis tendo como pano de fundo a norma. É por meio dela que as pessoas são interpretadas.

Logo, a anormalidade não está circunscrita apenas na figura do monstro, ela divide, para Foucault (2001), espaço com pelos menos mais dois personagens: o indivíduo a ser corrigido e o masturbador. E é preciso estabelecer as diferenciações entre essas três dimensões. O monstro é uma exceção, o indivíduo a ser corrigido tem uma frequência muito maior e o masturbador se caracteriza por um ritual que, embora velado, é praticamente universal. Além disso, o indivíduo a ser corrigido é incorrigível porque todas as tentativas cotidianas e familiares de correção não obtiveram êxito. E só há monstruosidade quando a transgressão do limite natural se refira ou questione a lei civil, religiosa ou divina: o que diferencia a monstruosidade da enfermidade, essa última prevista pelo direito.

O que faz com que esses três personagens tenham permanecidos distintos por tanto tempo é o fato de as instâncias de saber a que se referem serem separadas: o monstro se assenta na história natural, o indivíduo a ser corrigido nasce das técnicas pedagógicas e o masturbador é referido a uma nascente biologia da sexualidade. O controle das anomalias, por sua vez, irá sobrepor esses três personagens no século XIX, já que o anormal, nesse cenário, é um descendente desses três indivíduos. E considerando ser o monstro remetido à sociedade, o indivíduo a ser corrigido à família e o masturbador à intimidade/ao corpo, será a anormalidade "atacada" por todos esses vieses. E talvez continue a ser.

Para Foucault (2001), dispositivos de saber/poder como a psicotécnica, a psicanálise e a neuropatologia foram responsáveis pela passagem do monstro ao anormal. Para se justificar como ciência da higiene pública e proteção social, a psiquiatria precisava mostrar que conseguia perceber, ainda que outros até então não pudessem, um certo perigo e que isso provinha de seu conhecimento médico. Essa mesma lógica subjaz os diagnósticos que detectam doença onde os demais só enxergam comportamentos humanos. A mesma noção preventiva - de se antever crimes - passa a ser a regra na atualidade. Diagnósticos precoces e comportamentos preditivos.

Essa lógica em que tudo é diagnosticado parece também se relacionar com a dimensão da deficiência. Não apenas as deficiências clássicas (física, intelectual, auditiva e visual) são discursivizadas e reconhecidas. Quaisquer “desvios” - dislexia, disgrafia, transtorno do déficit de atenção e hiperatividade, dentre outros - são interpretados pelo senso comum como deficiência (ainda que oficialmente não sejam). Quase como na tentativa de nomear, para tratar e evitar uma "dificuldade maior".

No entanto, não podemos negar a notória positividade que emerge das práticas de normalização. Porque, ao lado de práticas muitas vezes violentas de apagamento do desvio, como veremos a seguir, essa sensibilidade propiciou fazeres que permitiram a educação e a manutenção das condições de nutrição e saúde das pessoas com deficiência. Determinadas ações que não só permitiram a literal sobrevivência das pessoas com deficiência - como também influenciaram uma narrativa (ainda em construção) de visibilidade. 


\section{A LIGA BRASILEIRA DE HIGIENE MENTAL}

Neste artigo realizamos uma breve análise dos arquivos da Liga Brasileira de Higiene Mental, exercício que nos dará uma dimensão dos princípios higienistas, da maneira como os psiquiatras se apropriaram da correção do anormal e, especialmente, de como as pessoas com deficiência eram significadas nessa conjuntura.

Os arquivos dizem respeito às publicações que compreendem o período de 1925 a 1946. A principal motivação para a criação dos arquivos era a difusão das ideias higiênicas e eugenistas e a troca de experiências entre pesquisadores do Brasil e do mundo. Esse material é composto por artigos dos mais renomados psiquiatras da época e de outros estudiosos dos assuntos afeitos ao tema: resenhas e comentários acerca das publicações mundialmente representativas das ideias higiênicas, atas das reuniões, bem como noticiários, campanhas promovidas e o estatuto da Liga de Higiene Mental também compunham esse montante.

É possível dizer que em consonância com os movimentos eugenistas e higiênicos que se propagavam pelo mundo, também no Brasil sentiu-se a ressonância desses dizeres e saberes. Já nas primeiras linhas da primeira das publicações, de 1925, é defendido o enorme peso que as deficiências e degenerações físicas exerciam sobre a coletividade: encargos financeiros rapidamente crescentes e significativa soma de infelicidade e sofrimento humanos. A higiene mental tem duas frentes de atuação: uma voltada às causas de degeneração física - é a profilaxia mental - e outra que buscava preparar o equilíbrio de adaptação entre a mentalidade individual e o meio físico e social - é a higiene mental propriamente dita.

Para "atacar" essa "problemática", acreditava-se que era preciso romper com a mera assistência médica e social, bem como com o simples trabalho de custódia - esse atrelado à construção de asilos, hospícios, casas de caridade, prisões e colônias - para os psicopatas, deficientes, criminosos, delinquentes, incapazes, indigentes e desempregados crônicos. Ou seja, medidas por eles questionáveis e que sempre se voltavam à condição já posta.

Essa ruptura se daria por meio da adoção de medidas de eugenia, ou seja, da diminuição dos malefícios da hereditariedade patológica, da regulamentação do casamento - por meio da segregação ou esterilização dos grandes deficientes - e pela restrição da entrada de imigrantes de mentalidade anormal

A lista é grande e ainda engloba a execução de meios de se evitar infecções como a sífilis e demais doenças que poderiam causar deficiências e transtornos mentais. Investir nos casos precoces, inclusive orientar mães e cuidadoras sobre autoridade e excesso de rigor que poderiam comprometer o futuro equilíbrio na vida adulta, também eram práticas recorrentes. Em outras palavras, tratavase de um verdadeiro empreendimento de profilaxia mental.

Importante destacar que as deficiências sensoriais também eram mencionadas pela Liga de Higiene Mental. É como se o déficit sensorial penetrasse na mente, como se a ausência de um sentido impedisse o pleno desenvolvimento das habilidades mentais. Ter saúde mental envolvia também a integridade dos sentidos. Aliás, noção que vai ao encontro daquela desenvolvida por Morel (apud CAPONI, 2012), uma vez que o psiquiatra entendia que os cegos e surdos, em virtude da privação de um sentido físico, poderiam apresentar um desenvolvimento moral nocivo.

Além do foco na população infantil/escolar, compreendida como aquela com idade ideal para promover o melhor desenvolvimento possível e evitar quaisquer desvios, há outros nichos que também preocupavam a Liga. Os imigrantes talvez fossem os que mais despertassem a apreensão dos higienistas. Era preciso proceder a um exame físico e mental de modo a só admitir os indivíduos sãos. Sobre isso, discorre Juliano Moreira (1925, p.108): "De nada nos servirá envidar esforços no sentido de melhorar as condições de saúde física e mental de nossa gente se tivermos sempre a chegar novas levas de tais indesejáveis".

E é exatamente esse o grande nó da imigração. Na época, considerando um Brasil escassamente povoado e extremamente carente de braços, na concepção do advogado Alvaro Cardoso (1925), não era conveniente impedir a imigração. Mas, no entanto, era preciso controlá-la. Porque o grande mote da Liga não era tão atrelado ao bem-estar das pessoas “desviantes", mas se voltava à fortificação de um país, por meio de ações que tornassem a população hígida e em níveis moral, físico e psíquico elevados. 
Desde muito que se vem procurando resolver o problema da imigração em nosso país. Mas, só em 1916, é que o Brasil começou a cogitar de se armar com medidas que visassem a defesa do país contra os denominados "indesejáveis", impedindo assim que o território nacional se tornasse o refugium peccatorum ${ }^{10}$ dessa classe de gente (CARDOSO, 1925, p. 141).

Xavier de Oliveira também advertia para a profilaxia mental dos imigrantes. Para ele há raças superiores e inferiores, sendo que as últimas colocavam em risco a formação eugênica do país. São apresentados por ele, em um dos artigos dos Arquivos de 1932, que há proporcionalmente mais psicopatas estrangeiros que brasileiros na população nacional. E ainda apontava que esses psicopatas procriavam uma leva de pessoas ainda mais miseráveis.

Oliveira (1932) justificava que essas pessoas deveriam ser barradas uma vez que já bastavam os nordestinos e planaltinos de Minas, Bahia, Mato Grosso e Goiás. Além de amazonenses - esses indiferentes à civilização - cuja inferioridade seria incontestável, e que marchavam felizmente para a extinção não muito longínqua. E são, por conseguinte, criadas uma série de leis que regulamentavam a entrada de estrangeiros, no sentido de que não se tornassem onerosos ao Estado, tampouco que degenerassem a população brasileira já suficientemente degenerada por pessoas de determinadas regiões, como mencionado há pouco. Nas palavras de Xavier de Oliveira (1932, p.35): “[...] jamais seremos uma grande nação se não cuidarmos de melhorar nossa raça”.

Há para a higiene mental dois problemas que se relacionam: (1) a estrutura física do indivíduo, não raramente deficiente e imperfeita - dependendo em grande parte da hereditariedade e (2) o meio físico e social, criando às vezes condições adversas que podem perturbar e no extremo até esmagar as mentalidades mais firmemente equilibradas. No entanto, raciocínio justo e deliberação correta poderiam ser treinados, com isso maus hábitos eram corrigidos pela prática repetida de atos.

Além disso, para a Liga, no pensamento de Heitor Carrilho (1925), a estagnação de um país, sua miséria e pouco desenvolvimento têm as faces de seus degenerados. É sobre eles que são despejadas as culpas e responsabilidades pelo não avanço de uma nação. Esse processo histórico resvala atualmente nas concepções que se têm sobre os indivíduos desviantes. E as práticas direcionadas a eles, em muitos casos, não se deslocaram. Na época do artigo de Carrilho (1925, p. 138), o programa de higiene mental se assentava nos seguintes princípios:

Começa ele no estabelecimento das regras concernentes à eugenia, afim de que sejam evitados os malefícios da hereditariedade patológica, estende-se pela puericultura pré e pós-natal e detém-se no fator educativo, cuja importância na formação do espírito é axiomática, permitindo aos indivíduos o afastamento dos hábitos mentais nocivos, aprimorando-lhes o caráter e traçando-lhes a personalidade íntegra. É, então, que se faz a educação dos instintos, dosando as reações que eles determinam e que tanto pesam na gênese dos delitos, influindo sobre essa "agressividade latente".

O internamento também era defendido nessa empreitada de higiene mental, conforme Moreira (1925, p. 113): "As internações não previnem apenas os delitos comuns, mas também os atentados contra a saúde mental da população, interrompendo a série de casos mórbidos hereditários. Tenho conhecimento de mais de uma série mórbida familiar descontinuada, graças à internação do indivíduo propagador do mal”.

\section{A PESSOA COM DEFICIÊNCIA PARA A LIGA BRASILEIRA DE HIGIENE MENTAL}

São identificadas dentre as publicações da Liga alguns artigos e notícias relacionados diretamente às pessoas com deficiência. Em 1933, e indo ao encontro daquilo que a Liga preconizava em relação ao tratamento da criança anormal, é publicado (na edição de

${ }^{10}$ Local de indulgência, ajuda e conforto. 
janeiro/março) um texto que discorria sobre o ensino das crianças anormais na Tchecoslováquia (FATOS E COMENTÁRIOS, 1933a). Os preceitos eram segregadores, no sentido de que a experiência era marcada pela constituição de classes especiais, divididas por deficiência. Em separado das crianças consideradas normais, recebendo atendimentos diferenciados, estavam: os meninos débeis mentais, as crianças difíceis, as paralíticas e aleijadas, os diminuídos da audição, os diminuídos da visão, os débeis físicos e os simplesmente débeis. Essas divisões e nomenclaturas marcam a compreensão que se tinha sobre a anormalidade na época ${ }^{11}$.

No mesmo ano, no exemplar referente aos meses de outubro a dezembro, consta nos arquivos a "Primeira publicação da Sociedade Pestalozzi de Minas Gerais” (FATOS E COMENTÁRIOS, 1933b). A missão dessa instituição deixa seu direcionamento claro e apontam quais são os preceitos eugenistas que atravessam a compreensão da deficiência: proteger a infância anormal e preservar a sociedade e a raça das influências nocivas da anormalidade mental. Considera-se anormal todo ser que por sua condição hereditária ou acidentes mórbidos ocorridos na infância, que por falta de inteligência ou caráter, não é capaz de adaptar-se à vida social com recursos da família ou escola pública, suficientes para a maioria das crianças na mesma idade. Além de individualizar claramente o déficit, a meta da Sociedade Pestalozzi, e da Liga, é melhorar o estado da criança anormal para que pese o menos possível para a sociedade.

Em 1943, Alberto de Lira Cavalcante publica um artigo que trata das crianças anormais. Ele traz três categorias para essas crianças: os retardados educáveis, os difíceis e os irremediavelmente ineducáveis. Nessa última subdivisão temos os idiotas e os imbecis, ambos com graves lacunas psíquicas. Cavalcante ressalta que dentre os oligofrênicos ${ }^{12}$ profundos, idiotas e imbecis, não se consideram os anormais físicos e os sensoriais. Aqui se percebem sinais da dissolução da relação entre integridade sensorial e mental (intelectual).

Cavalcante ressaltava que se o idiota e o imbecil conseguem melhorar, os simples escolares difíceis, débeis ou constitucionais deveriam ser cuidados com urgência. Dentre os tratamentos possíveis, aponta o opoterápico (uso de drogas de origem animal), o helioterápico (utilização da luz solar), a melhor alimentação e as regras pedagógicas, dentre outros. Esse controle da população, bem como o estabelecimento de estatísticas e parâmetros e apagamento do déficit, são notórios no trecho que segue:

Temos assim uma tarefa mais alta e que é muito mais do que simplesmente instruir e que é de prevenir e curar o infante nacional, eivado de uma, duas e mais infecções, cheios de taras, vícios e deformidades físicas, distúrbios nervosos e mentais [...]. O que desejo demonstrar neste sumário trabalho é a facilidade que o exame periódico de saúde vem proporcionar às equipes encarregadas dos exames periódicos a pegar em flagrante o pequeno deficiente mental e ter assim, à mão, um material magnífico donde poderá sair um monumento grandioso em relação à biotipologia e à caracteriologia brasileira e todas as sequências biológicas (CAVALCANTE, 1943, p. 18).

Ernani Lopes (1930), no entanto, em resenha sobre o trabalho de Wallace, um proeminente higienista estadunidense, traz argumentos que contrariam a correlação entre deficiência intelectual e delinquência. Para o autor, a constatação de que há mais pessoas de baixo QI dentre os detentos, em comparação com a população em geral, é ilusória. Lopes enfatiza que os débeis mentais são mais vulneráveis, mais facilmente recolhidos pela polícia e com menos repertório para argumentar em julgamentos (mais ingênuos, sentido atualizado ainda hoje). O que ocorre no débil mental é que seu déficit mental se sobressai ao moral, enquanto que para aqueles com inteligência normal, é o moral que está prejudicado. Daí decorre que a aplicação sistemática de medidas de higiene mental seria um meio profícuo de minimizar a delinquência.

\footnotetext{
${ }^{11}$ Essas noções fomentaram, na época, a abertura de uma série de instituições especializadas na pessoa com deficiência, de cunho educacional. Outras já existiam como é o caso do Instituto Benjamin Constant - com atuação até o presente momento - e do Instituto Nacional de Educação de Surdos, também em funcionamento (LANNA JUNIOR, 2010). A AACD (Associação de Assistência à criança deficiente - antes o "d" se referia à defeituosa) e a APAE (Associação de Pais e Amigos dos Excepcionais) nascem na década de 50, do século XX, no Brasil e têm cunho reabilitador no primeiro caso e mais voltado à educação no segundo. Entretanto, todas essas instituições ainda mantêm o caráter de centros especializados, voltados à reabilitação.

${ }^{12}$ Oligofrenia é um termo que diz respeito ao prejuízo da inteligência no ser humano. De origem médica, tem as seguintes subdivisões: oligofrenia leve, moderada e profunda. Cada uma dessas divisões tem um correlato: debilidade, imbecilidade e idiotia, respectivamente. Porém, os últimos termos não mais são utilizados pelo caráter pejorativo que adquiriram. De qualquer modo, oligofrenia é um termo médico e menos utilizado na atualidade sendo mais usual o termo deficiência intelectual. Na época de produção dos arquivos, a deficiência intelectual, relativa à cognição, era chamada de mental - por esse motivo o termo aparece ao longo do texto.
} 
De acordo com Souza e Boarini (2008), que pesquisaram a deficiência mental na concepção da Liga Brasileira de Higiene Mental, o ensino voltado à pessoa com deficiência ficava restrito aos hábitos higiênicos e alimentares, além da aquisição de algumas regras sociais. Havia também a preocupação em preparar, de acordo com as condições, os jovens para atividades de trabalhos simples. As pesquisadoras referem ainda que:

\begin{abstract}
A análise do atendimento escolar oferecido ao deficiente mental nas primeiras décadas do século XX, segundo o ideário higienista, nos revela que a defesa da educação dos indivíduos com deficiência mental foi feita em nome da "ordem e do progresso", pois que evitaria a proliferação de criminosos e desajustados de toda espécie, ao mesmo tempo em que implicaria a economia dos cofres públicos e dos bolsos de particulares, diminuindo gastos com a manutenção de manicômios, asilos e penitenciárias (SOUZA; BOARINI, 2008, p. 289).
\end{abstract}

Em suma, vale destacar que ao longo das publicações dos Arquivos da Liga são percebidas algumas temáticas constantes: o foco na infância, a tônica na educação e as insistentes campanhas antialcoolismo. Outro assunto presente dizia respeito à problemática que cercava os imigrantes: a possibilidade de entrada de estrangeiros degenerados - uma vez que a atuação da Liga compreendeu os períodos entre e pós-guerras - foi uma questão que também alinhavou essa complexa trama eugênica brasileira. E a pessoa com deficiência também esteve presente, ora sendo abordada no viés corretivo, de atendimento educacional diferenciado, ora com a conotação de aniquilação.

Sobre a aniquilação, Kehl (1932, p.08), em um dos artigos da Liga, defende que é a generosidade social indiscriminada que propicia "[...] o amontoamento de resíduos humanos que a natureza não conseguiu eliminar a seu tempo". Kehl (1932) estabelece ainda uma relação direta entre a degeneração e a desocupação, entre eugenia e trabalho/produtividade.

O problema máximo, em suma, é o da geração. E para este só há o remédio do tempo, associados aos remédios propostos por Galton: reduzir até eliminar, paulatinamente, por processos biológicos, os subnormais e anormais, impedindo a reprodução de indivíduos apresentando taras nervosas e físicas; incentivar o orgulho pela verdadeira nobreza de estirpe, consubstanciada na saúde integral; promover a união conjugal de eugenizados; melhorar, progressivamente, as condições de meios de educação (KEHL, 1932, p. 9).

Os postulados de Kehl (1932) são duros e culpabilizam as pessoas nomeadas como anormais de todos os males da sociedade, ele chega a mencionar que atritos familiares, sociais e até os de ordem internacional são causados pelos anormais e que é justamente a presença dessas pessoas que atrasa e impede o movimento da humanidade rumo ao ideal. Além de considerados moralmente inferiores, também são tidos como imprestáveis, o que ratifica essa noção de invalidez, de fardos que precisam ser carregados pela sociedade.

Esse tipo de saber-poder produzido sobre o anormal fomentava a exclusão e até mesmo o extermínio. Eram discursos como esses, aliás legitimados, já que propagados por figuras de notório saber e de posição de destaque na sociedade, como eram os médicos e membros da Liga, que propiciaram a condição de possibilidade para que ideias nazistas fossem empregadas e apoiadas por muitos.

Em suma, essa redução dos anormais e débeis mentais, que para Kehl (1932) aumentavam assustadoramente, se faria pela esterilização compulsória de determinados indivíduos e por meio da prática da filantropia seletiva, ou seja, dar auxílio apenas aos mais fortes, aos tipos superiores da população. É o extermínio da diversidade, por meio de um processo seletivo que nada tem de natural.

À maneira de Foucault (2005b), quanto mais os degenerados, os anormais e as espécies inferiores desaparecerem, mais forte e vigorosa será a raça. Nessa perspectiva, a vida se torna mais sadia com o aniquilamento da pessoa com deficiência. E não se trata apenas da vida individual, mas também da vida da população. 


\section{CONSIDERAÇÕES FINAIS}

Pelos arquivos analisados, foi possível perceber a forma como o desvio era abordado. A aniquilação/minimização da deficiência não tinha a conotação de integrar a pessoa à sociedade - prática mais atual - mas de preservar o meio dos malefícios e especialmente dos encargos, do peso que as deformidades poderiam trazer. No limite, era o extermínio da diversidade, ou seja, tratava-se de uma empreitada biopolítica, de controle dos corpos e da população; suas deficiências e eventualidades (FOUCAULT, 2005b).

Entretanto, não podemos deixar de destacar esse efeito positivo que advém do investimento biopolítico, uma vez que o controle dos corpos instituiu também práticas de cuidados, de assistência e de benefício às pessoas com deficiência. Essa ação passou a ser, inclusive, uma das dimensões da função do Estado - esperada e exigida dele. A concessão desses apoios, aliás, atingiu o status de virtude e benevolência, uma vez que profissionais que trabalham com pessoas com deficiência são comumente vistos como "anjos evoluídos", ou seja, qualquer benefício concedido às pessoas com deficiência, ainda hoje, tem ares misericordiosos.

No entanto, nas publicações da Liga, deficiência intelectual e degenerações físicas - muito mais do que dimensões a serem investidas/tratadas - eram discursivizadas como enormes pesos à coletividade e as deficiências sensoriais como barreiras ao pleno desenvolvimento das habilidades mentais. Essa sensibilidade explica muitos dos discursos que ainda se repetem; essencialmente aqueles que enunciam a deficiência como um risco, como algo que precisa ser evitado, apagado e que sua inevitabilidade culminaria em perda, incapacidade, prejuízo e invalidez. Pela análise dos textos dispostos nos arquivos da Liga, é possível dizer que as pessoas com deficiência eram significadas sob o regime de inferioridade, de atraso à nação, de mal que deveria ser tratado/aniquilado. E, em alguma medida, ainda são.

Esse é o dilema da deficiência - categoria que se pretende naturalizada, uma vez que inerente à vida e, sobretudo, ao envelhecimento - mas que notoriamente se quer evitar. É nessa ambiguidade de sentidos, aparentemente tão antagônicos, que se encontra a deficiência. Tenta-se romper com os sentidos que a remetem ao desfortúnio, à desgraça, à falta de sorte, mas a deficiência é comumente discursivizada como um risco.

Por fim, instituir processos de inclusão demanda a compreensão de que o ambiente é determinante para a funcionalidade da pessoa com deficiência, rompendo sobretudo com: (1) o viés individualizante, (2) o sentido de tragédia pessoal que se atrela à deficiência e (3) a vontade de apagamento dos seus sinais (processos de reabilitação, de aproximação com a normalidade). Incluir passa prioritariamente pelo exercício de revisitar os sentidos que ainda encerram a deficiência no corpo, que a enunciam como um peso à coletividade, conforme discursivizado pelos arquivos analisados. Considerando que a deficiência não deve ser entendida como um problema individual, mas uma questão da vida em sociedade (OLIVER, 1983, 1996; GESSER, NUERNBERG; TONELI, 2012), a forma como a sociedade se organiza - e produz saberes - é que tem imposto um grande peso às pessoas com deficiência.

\section{REFERÊNCIAS}

AGAMBEN, G. Homo Sacer. O poder soberano e a vida nua I. Belo Horizonte: Editora Universidade Federal de Minas Gerais, 2002.

ASSOCIAÇÃO AMERICANA DE PSIQUIATRIA, APA. DSM V - Manual diagnóstico e estatístico de transtornos mentais. 5. ed.rev. - Porto Alegre: Artmed, 2014.

BRASIL. LEI N ${ }^{\circ}$ 13.146, DE 06 DE JULHO DE 2015. Institui a Lei Brasileira de Inclusão da Pessoa com Deficiência (Estatuto da Pessoa com Deficiência), Brasília, DF, 2015. Disponível em: http://www.planalto.gov.br/ccivil 03/ ato20152018/2015/lei/l13146.htm. Acesso em: 10 mar. 2017.

CANGUILHEM, G. O normal e o patológico, trad. Maria Thereza Redig de Carvalho Barrocas e Luiz Octavio Ferreira Barreto Leite. 6. ed. Rio de Janeiro: Forense Universitária, 2009. 
CAPONI, S. Da compaixão à solidariedade: uma genealogia da assistência médica. Rio de Janeiro: Fiocruz, 2000.

CAPONI, S. Biopolítica e medicalização dos anormais. Physis, Rio de Janeiro, v.19, n.2, p.529-549, 2009.

CAPONI, S. Loucos e degenerados: uma genealogia da psiquiatria ampliada. Rio de Janeiro: Editora Fiocruz, 2012.

CAPONI, S. O DSM-V como dispositivo de segurança. Physis Revista de Saúde Coletiva, Rio de Janeiro, v. 24, n. 3, p. 741-763, 2014.

CARDOSO, Á. Subsídios à legislação sobre imigração. Arquivos Brasileiros de Higiene Mental, Rio de Janeiro, v. 1, n. 2, p. 141-146, 1925.

CARRILHO, H. Considerações sobre profilaxia mental e delinquência. Arquivos Brasileiros de Higiene Mental. Rio de Janeiro, v. 1, n. 1, p. 131-140, 1925.

CAVAlCANTE, A. L. Crianças Anormais. Arquivos Brasileiros de Higiene Mental, Rio de Janeiro, v. 14, n. 1, p. $17-20,1943$.

DELEUZE, G. Foucault. São Paulo: Brasiliense, 2013.

DINIZ, D. O que é deficiência. São Paulo: Editora Brasiliense; 2007. 96 pp. (Coleção Primeiros Passos, 324).

FATOS E COMENTÁRIOS. O ensino das crianças anormais na Tchecoslováquia. Arquivos Brasileiros de Higiene Mental, Rio de Janeiro, v. 6, n. 1, p.57-62, 1933a.

FATOS E COMENTÁRIOS. A primeira publicação da Sociedade Pestalozzi de Minas Gerais. Arquivos Brasileiros de Higiene Mental, Rio de Janeiro, v. 6, n. 3, p.328-335, 1933 b.

FOUCAULT, M. Microfísica do poder. Trad. Roberto Machado. Rio de Janeiro: Graal, 1979.

FOUCAULT, M. A ordem do discurso. São Paulo: Loyola, 1996.

FOUCAULT, M. A arqueologia do saber. Rio de Janeiro: Forense Universitária, 1997.

FOUCAULT, M. Os anormais. São Paulo: Martins Fontes, 2001.

FOUCAULT, M. O nascimento da clínica. Rio de Janeiro: Forense Universitária, 2004a.

FOUCAULT, M. "A ética do cuidado de si como prática da liberdade". In: FOUCAULT, M. Ditos \& escritos V - ética, sexualidade, política. Rio de Janeiro: Forense Universitária, 2004b. p. 264-287.

FOUCAUlT, M. História da sexualidade I: a vontade de saber. Trad. Maria Thereza da Costa Albuquerque e J. A. Guilhon Albuquerque. 16.ed. São Paulo: Graal, 2005a.

FOUCAUlT, M. Em defesa da sociedade. São Paulo: Martins Fontes, 2005 b.

FOUCAUlT, M. Nascimento da biopolítica. São Paulo: Martins Fontes, 2008a.

FOUCAULT, M. Segurança, território, população. Martins Fontes. São Paulo, 2008b. 
GESSER, M.; NUERNBERG, A. H.; TONELI, M. J. F. A contribuição do Modelo Social da Deficiência à Psicologia Social. Psicologia \& Sociedade, v.24, n.3, p. 557-566, 2012.

HARLOS, F. E.; HARLOS, F. C. G.; DENARI, F. E. Origens da categoria "deficiente” e da educação especial (re)pensada. Revista Géfyra, São Miguel do Iguaçu, v. 1, n. 2, p. 95-105, jul./dez. 2012.

KEHL, R. F. Considerações em torno da pletora humana. Arquivos Brasileiros de Higiene Mental. Rio de Janeiro, v. 5, n. 2, p. 5-10, 1932.

LANNA JUNIOR, M. C. M. (Comp.). História do Movimento Político das Pessoas com Deficiência no Brasil. - Brasília: Secretaria de Direitos Humanos. Secretaria Nacional de Promoção dos Direitos da Pessoa com Deficiência, 2010.

LIMA, F.; COSTA, B. Modelos e evolução das perspectivas sobre deficiência. 2014. Trabalho realizado no âmbito do curso Inclusão e Acesso às Tecnologias - Mooc 2014. Disponível em:<http://www.scribd.com/doc/219218159/Modelos-e-evolucao-dasperspetivas-sobre-deficiencia\#scribd. Acesso em: 17 dez. 2015.

LOPES, C. A. Introdução ao estudo da higiene mental. Arquivos Brasileiros de Higiene Mental, Rio de Janeiro, v. 15, n. 1, p.69-71, 1944.

LOPES, E. Serão os débeis mentais criminosos? Arquivos Brasileiros de Higiene Mental, Rio de Janeiro, v. 3, n. 1, p. 22 -23, 1930.

MINISTÉRIO DA SAÚDE. Exames da Triagem Neonatal. Disponível em: http://portalms.saude.gov.br/saude-para-voce/saudeda-crianca/pre-natal-e-parto/exames-de-triagem-neonatal. Acesso em: 02 maio 2018.

MOREIRA, J. A seleção de imigrantes no programa da higiene mental. Arquivos Brasileiros de Higiene Mental. Rio de Janeiro, v. 1, n. 1, p. 109-115, 1925.

OLIVEIRA, X. Da profilaxia mental dos imigrantes. Arquivos Brasileiros de Higiene Mental. Rio de Janeiro, v. 5, n. 1, p. 16-38, 1932.

OLIVER, M. Social work with disabled people. London: MacMillan, 1983.

OLIVER, M. Defining impairment and disability: issues at stake. In: BARNES, C.; MENCER, G. Exploring the divide: illness and disability. Leeds: Disability Press, 1996. p. 11-16.

PACHECO, K. M. B.; ALVES, V. L. R. A história da deficiência, da marginalização à inclusão social: uma mudança de paradigma. Acta Fisiátrica, v. 14, n. 04, p. 242-248, dez. 2007.

PEREIRA, R. Diversidade funcional: a diferença e o histórico modelo de homem-padrão. História, Ciências, Saúde. Manguinhos, Rio de Janeiro, v.16, n.3, jul-set., p.715-728, 2009.

PESSOTTI, I. Deficiência mental: da superstição à ciência. São Paulo: Edusp, 1994.

[ET, C. Traité de métapsychique. Paris, Librairie Félix Alcan, 1922

SASSAKI, R.K. Inclusão: construindo uma sociedade para todos. Rio de Janeiro: WVA, 1997. 
SEIXAS, A. A. A; MOTA, A; ZILBREMAN, M. L. A origem da Liga Brasileira de Higiene Mental e seu contexto histórico. Revista de Psiquiatria do Rio Grande do Sul, v.31, n.1, p.82-82, 2009.

SOUZA, M. L.; BOARINI, M. L. A deficiência mental na concepção da Liga Brasileira de Higiene Mental. Revista Brasileira de Educação Especial, Marília, n.14, p. 273-292, maio-ago., 2008.

UNIVERSIDADE ESTADUAL DE MARINGÁ. Grupo de estudos e pesquisas higiene mental e eugenia. Arquivos da Liga Brasileira de Higiene Mental. Disponível em: http://old.ppi.uem.br/gephe/index.php/arquivos-digitalizados/14-sample-data-articles/85arquivos-brasileiros-de-higiene-mental. Acesso em: 12 mar. 2017.

WALBER, V. B; SILVA, S. N. As práticas do cuidado e a questão da deficiência: integração ou inclusão? Estudos de Psicologia, Campinas, v. 23, n.1, p. 29-37, mar. 2006. 